NUNES, Luciana Borre. As imagens que invadem as salas de aula: reflexões sobre cultura visual. Ideias\&Letras: Aparecida/SP, 2010, 184 páginas.

\title{
Resenha: Problematizando Práticas Pedagógicas e Infâncias Através da Cultura Visual
}

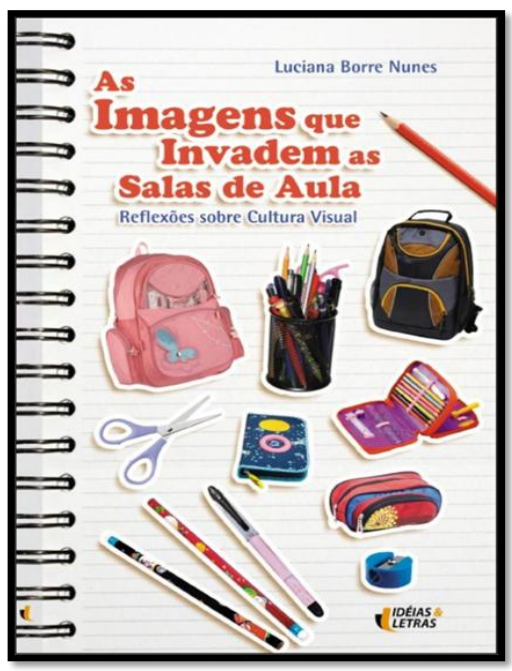

As imagens que invadem as salas de aula: reflexões sobre cultura visual, livro lançado em 2010, é uma obra que apresenta reflexões acerca da constituição das Infâncias através das inúmeras imagens que cercam o cotidiano. O trabalho busca pesquisar, refletir, conhecer e mostrar as características das infâncias contemporâneas, quais aspectos interferem na sua constituição e como ela vem sendo concebida, bem como seu desenvolvimento. A instituição escolar, um dos cenários de construção da cultura, permeia toda a obra.

Busca desafios ao abordar a temática da cultura visual no ambiente escolar, destacando a contribuição das imagens na composição dos olhares sociais e da produção de subjetividades nos sujeitos envolvidos. Essas imagens contribuem para a composição dos olhares sociais, através dos quais percebemos as diversas identidades e representações sócio-culturais.

O primeiro capítulo intitulado Primeiras Marcas proporciona reflexões acerca dos Estudos Culturais numa perspectiva pós-estruturalista, acreditando que inúmeras contribuições e questionamentos poderão surgir sobre as práticas educativas adotadas nas escolas e sobre os "novos" estudantes que encontramos nas salas de aula. É nesse capítulo que a autora apresenta as conceituações sobre constituição de identidades, representações e subjetividades. 
Também destaca que, cotidianamente, os estudantes evidenciam que suas identidades são construídas por um imenso repertório de imagens. A escola é invadida por mochilas, cadernos e outros materiais escolares decorados pelas imagens dos personagens preferidos das crianças (que muitas vezes não permanecem nessa preferência por mais de três semanas). Essas vivem numa sociedade de consumo, onde as imagens contribuem significativamente para compor o desejo de compra de produtos destinados ao público infantil feminino e masculino. Assim, as salas de aula tornaram-se cenários pertinentes a um estudo relacionado à Cultura Visual.

Diante disso, tais discussões ainda não são presenciadas entre os profissionais da educação nas escolas. As práticas escolares adotadas em outros períodos históricosociais já não atendem às necessidades que o nosso tempo exige. A escola parece ainda querer manter as mesmas concepções de ensino que já não correspondem às transformações que o âmbito social apresenta. Hernández (2007, p. 38) sugere que a escola deve rever suas práticas educativas para adaptar-se às necessidades dos educandos e que "...todas as concepções e práticas pedagógicas podem e devem ser questionadas. [...] A partir daí é que surge a necessidade de colocar em questionamento as práticas de naturalização que hoje circulam e se mantêm como dogmas na educação". A autora afirma que vivenciamos a facilidade de acesso a um grande número de informações que são múltiplas e incertas, e isso modifica as relações entre o sujeito e o conhecimento. Essa realidade reconfigura o processo de ensino e de aprendizagem no momento em que já não podemos esperar a centralidade de conhecimentos na escola. Devido a isso, é crescente a necessidade daquilo que Pozo (2002) chama de Gestão do Conhecimento, onde a formação dos estudantes deveria estar voltada para sua autonomia (aprendendo a buscar, selecionar e interpretar criticamente as informações) e que, a partir disso, possam produzir contínuas aprendizagens. O mesmo autor (2002, p. 48) afirma que vivemos na sociedade do conhecimento e que, por esse motivo, as atribuições das instituições escolares se modificaram: "En la sociedad de la información la escuela ya no es la fuente primera, y a veces ni siquiera la principal, de conocimiento para los alumnos en muchos dominios. Son muy pocas ya las primicias informativas que se reservan para la escuela."

As práticas escolares ainda se mostram defasadas, pois procuram constantemente enquadrar seus educandos em uma única linha de formação, sem articular à sala de aula as problemáticas que estão "em alta" em todos os outros campos sociais. Entre essas, se encontram as artes visuais da contemporaneidade, que através da Cultura Visual, buscam desestabilizar nossos sentidos e provocar diferentes leituras e interpretações. A Cultura Visual contemporânea utiliza as novas ferramentas tecnológicas, como a fotografia digital e a informatização, para promover olhares diferenciados sobre as temáticas do cotidiano. 
No segundo capítulo intitulado $A$ cultura visual nas escolas, há a apropriação das concepções de arte/educadores, principalmente Fernando Hernández (2000, 2007), para falar sobre as imagens que "invadem" as salas de aula e que, através de uma Cultura Visual cada vez mais dinâmica, acabam instaurando maneiras de ser e de agir socialmente, constituindo nossas representações sobre o mundo.

Uma das problematizações que surge nesse capítulo está relacionada com a realização de atividades artísticas em sala de aula, pois visualiza um grande envolvimento dos estudantes e o relato de aprendizagens (articuladas com outras áreas do conhecimento) e de experiências pessoais que ultrapassam os limites físicos da escola. Muitas falas das crianças relacionam suas experiências estéticas e as habilidades artísticas a "dons" que, geralmente, são característicos das destrezas manuais femininas. Diversos relatos, que atribuem às meninas a agilidade com trabalhos de cunho manual, instigam reflexões para uma tentativa de compreensão sobre a origem de tais concepções e como essas ilustram as representações de ser menina na atualidade. Junto a isso, também há uma significativa "invasão" de imagens nas salas de aula que marcam, por exemplo, a distinção entre brinquedos e personagens dos meninos e das meninas.

Outra inquietação diz respeito à ausência de discussões sobre uma cultura visual no ambiente escolar, embora seja rotineiro encontrá-la, não somente em meio aos estudantes, mas em todas as instâncias da vida. Estamos submersos em uma sociedade imagética, onde somos constantemente produzidos por imagens. As imagens contribuem para a composição dos olhares sociais e através delas percebemos as diversas identidades e representações. Produzimos e interagimos com imagens que expressam aquilo que pensamos sobre as coisas.

Além disso, as instituições escolares enfrentam dificuldades para atender a demanda de uma geração que está imersa numa cultura visual dinâmica, rápida e marcada pelos avanços tecnológicos. As crianças e os jovens da contemporaneidade estão diante de novas maneiras de agir e de pensar socialmente. Vivenciam a força do mercado de consumo, as relações sociais contemporâneas e os constantes investimentos midiáticos. Com isso, estabelecem relacionamentos diferenciados de outros tempos históricos com as instituições escolares, porque seu contexto social exige maior dinamicidade e conhecimento no manejo das ferramentas tecnológicas e maior reflexão sobre as diferenças no convívio social.

Posteriormente, no terceiro capítulo chamado A cultura visual produzindo gênero, a autora apresenta um recorte da dissertação ("Meninas são doces e calmas": um estudo de Gênero através da Cultura Visual) defendida em dezembro de 2008 na Pontifícia Universidade Católica do Rio Grande do Sul. Nesse capítulo são mostradas considerações sobre como as imagens contribuem para a produção de subjetividades femininas e sobre 
como as meninas do Ensino Fundamental manifestam suas representações de feminilidade no âmbito escolar.

Uma dessas "verdades", encontradas durante o terceiro capítulo está relacionada ao imaginário de beleza física ideal procurado, constantemente, pelas meninas. O corpo almejado pelas estudantes é produzido, fabricado e moldado culturalmente, pois as imagens com as quais elas convivem dizem como esses devem ser esculpidos e revestidos. As meninas vivenciam discursos visuais que instauram o desejo pelo corpo magro, dinâmico e fashion. Assim, as crianças estão diante de um conjunto de "regras" para o desenvolvimento de seu corpo, ainda infantil, e desde cedo já aprendem e seguem as normalidades vigentes.

Dessa maneira, o universo visual exerce pedagogias, pois as imagens nos ensinam a olhar as situações sociais, nos educam. Elas também mostram e constituem quais os produtos que devem ser consumidos pelas crianças, configurando os relacionamentos sociais através das condições de consumo. Nesse caso, os estudantes apresentam a necessidade de aquisição constante de produtos que têm destaque e significativa circulação entre os componentes da turma em sala de aula. Isso é fomentado por uma avalanche de imagens que circulam, articuladamente, na mídia televisiva, na mídia impressa e na internet.

Além disso, os desejos de compra das crianças são dinâmicos e mutáveis, pois é possível obter qualquer produto com rapidez, usufruir dele por pouco tempo, descartá-lo e procurar um novo material para voltar a adquirir.

Também é preciso considerar que ao adquirir uma boneca, um caderno, uma roupa ou qualquer outro tipo de acessório, as crianças não estão consumindo somente um produto, mas sim toda uma rede de representações que ensina como as meninas devem ser, agir e pensar. Elas não consomem, unicamente, a imagem das princesas ou da Barbie, mas também seu estilo de vida e suas histórias.

Diante dessas considerações, as inquietações tornam-se ainda mais fecundas, pois, enquanto professora, ela apresenta responsabilidades e comprometimentos perante a educação dos olhares sociais dos estudantes. Hernández (2007, p. 77) ressalta a importância que os educadores detêm na incumbência de promover novos e diferentes olhares sobre a constituição de gênero: "...é necessário que os professores auxiliem as meninas a compreenderem que as imagens das mídias e da cultura visual sobre a feminilidade e sobre o que é ser mulher dão forma a suas identidades e influenciam meninos e rapazes na construção de sua masculinidade."

Por isso, as reflexões realizadas no decorrer do livro desconfortam as posições adotadas pelas instituições escolares, pois as fazem pensar sobre os relacionamentos interpessoais contemporâneos, sobre os "novos" sujeitos que estão inscritos no âmbito escolar, sobre as diferentes realidades culturais transgredidas pela tecnologia, sobre a configuração 
recente do consumo, sobre como o corpo é, atualmente, moldado, e sobre o imenso repertório visual no qual todos estamos imbricados. Novos relacionamentos, antes impensáveis pelas escolas, atravessam as salas de aula, promovendo o contato com múltiplos saberes, modos de vida, sujeitos e valores de convivência social.

Embora no campo da educação seja comum a pretensão de apontar "receitas", diretrizes e soluções, os percursos teóricos, as reflexões e as sugestões de projetos pedagógicos expostos no livro não pretendem mostrar o quanto as imagens ou outros artefatos culturais são maléficos ou negativos, e nem marcar os caminhos mais seguros para uma educação de qualidade. O que a obra procura problematizar é como as imagens instauram maneiras de ser e de pensar e como produzem conhecimentos considerados únicos e verdadeiros. Com isso, as discussões procuram inquietar e desacomodar algumas verdades, tão caprichosamente consolidadas, e apontar possibilidades de pensarmos sobre as relações que temos com o mundo visual.

Por fim, no capítulo Trocando experiências de sala de aula, apresenta o relato de sete projetos de trabalhos sobre a Cultura Visual desenvolvidos com crianças da Educação Infantil e de Séries Iniciais do Ensino Fundamental. Com isso, a autora busca comprovar que a Cultura Visual pode ser trabalhada de maneira legítima e significativa nas salas de aula.

Para concluir, considero que essa obra pode servir de subsidio relevante à prática educacional, bem como pode promover novas pesquisas e trabalhos que representem avanços no contexto brasileiro educacional.

\section{Referências Bibliográficas:}

HERNÁNDEZ, Fernando. Cultura visual, mudança educativa e projeto de trabalho. Porto Alegre: Artmed, 2000.

. Catadores da Cultura Visual: proposta para uma nova narrativa educacional.

Porto Alegre: Mediação, 2007.

NUNES, Luciana Borre. As imagens que invadem as salas de aula: reflexões sobre cultura visual. São Paulo: Ideias \& Letras, 2010.

POZO, Juan Ignácio. Aprendizes e mestres: a nova cultura da aprendizagem. Porto Alegre: Artmed, 2002. 